\title{
Nitrates in Drinking Water -A Beneficial Effect against Cancer
}

\author{
Vishal Shah ${ }^{1 *}$ and Anand Shah ${ }^{2}$ \\ ${ }^{1}$ College of the Sciences and Mathematics, West Chester University, USA \\ ${ }^{2}$ Charles F Patton Middle School, Kennett Square, PA, USA
}

Submission: May 19, 2020; Published: June 02, 2020

*Corresponding author: Vishal Shah, College of the Sciences and Mathematics, West Chester University, PA 19382, USA

Abstract

Nitrates in drinking water have been hypothesized to cause cancer. In the current meta-data analysis based study, we investigate if populations having high nitrate concentrations in drinking water have increased incidence rates of cancer. The hypothesis was tested using the county level cancer incidence rate data obtained from the Center for Disease Control, and nitrate data obtained from the individual water system's consumer confidence reports. Results indicate that a nitrate concentration in drinking water does have a preventative effect on the Kidney and Renal Pelvic, Larynx, Lung and Bronchus, and Oral and Pharynx cancers. Analyzing the results based on sex and race, results show that nitrate in drinking water has a more preventative effect on the white population, irrespective of sex. For the Black and Hispanic population, the effect was pronounced in the male populations. Overall, the results show that, within the safe limits, nitrates in drinking water could have beneficial roles.

Keywords: Nitrates; Drinking water; Incidence rates of cancer; Correlation analysis; Regression models

\section{Introduction}

While cancer remains the leading cause of death in the United States, there exists a large disparity in the incidence and mortality rates between different states [1-4]. Beyond genetic inheritance, environmental factors are having been linked to mutations leading to causation of cancer. Some of the examples of environmental factors include tobacco use, excessive sun exposure, and exposure to known carcinogens in various settings. Contamination of drinking water by nitrate has also been known as an environmental factor leading to increased cancer incidence rates [5]. Over the past decade, numerous cohort-based observational studies have reported the possible link between nitrate concentration in drinking water and the incidence rates of cancer [6-9]. Basic consumer oriented literature lists nitrates as a possible carcinogen and to that extent, the Safe Drinking Water Act passed by the United States Congress requires all public water systems to report the nitrate concentration in the annual consumer confidence reports (CCRs). Environmental Protection Agency (EPA) has set a limit of $10 \mathrm{ppm}$ or $\mathrm{mL} / \mathrm{g}$ for Nitrate as Nitrogen in drinking water (Code of Federal Regulations (40 CFR 141)). However, there has been no metadata analysis at a national level investigating the link between nitrate concentrations and incidence rates of cancer. The primary reason for the lack of study is the absence of central repository from where nitrate data can be obtained with ease. One has to search for an individual CCR for a given year and treatment system. For any analysis at national level, this process is daunting.

Further, numerous studies reported in the literature linking population exposure to carcinogens and incidence rate of a given cancer are carried out using state level data. However, not all population within a given state will be exposed to a carcinogen uniformly. With county level cancer incidence rates data now available; one needs to use this to have a better understanding of the relationship between carcinogen exposure and cancer.

The current study reports for the first time the relationship between nitrate concentration in drinking water and incidence rates of cancer, with the resolution of the data used at the county level. We test the hypothesis that populations receiving drinking water with high nitrate concentrations in drinking water will have increased incidence rates of cancer.

\section{Materials and Methods}

19 states were randomly selected across the U.S. They were Alabama, Arizona, Arkansas, California, Connecticut, Georgia, Idaho, Iowa, Massachusetts, New Hampshire, New Jersey, New York, Oklahoma, Pennsylvania, South Carolina, Texas, Utah, Washington, and Wisconsin. Using the EPA's SDWIS search engine, 
a list of drinking water systems serving more than 100,000 people along with the population and county that the system serves was obtained (https://www.epa.gov/enviro/sdwis-search). For New Hampshire and Utah, water systems that are serving 10,000 to 100,000 population range were added as well. The rationale for selecting these systems was because of the lack of CCRs for smaller systems and to ensure the collection of data for all drinking water systems serving the population does not become time prohibitive. On each water system's website, available Consumer Confidence Reports were downloaded and values of the maximum nitrate concentration present in drinking water was transcribed. All the nitrate data was downloaded for the years between 2012 and 2017. Average of the maximum values for each of the counties was calculated prior to being used in the analysis as the independent variable. The Center for Disease Control (CDC)'s database was used to obtain the age-adjusted incidence rate of Cancer per 100,000 population cancer for the time frame 2011-2015 at the county level (https://ephtracking.cdc.gov/DataExplorer/\#/). All Cancer types for which the data were available at the county level were selected in the study. Total annual precipitation data were collected from the National Oceanic and Atmospheric Administration website. All water systems that covers multiple counties were deleted prior to both data analyses. Pearson correlation analyses and linear regression analyses were carried out using Statistica v13.3.

We acknowledge the discrepancy in the time duration. However, the reason for the selected time frame is the lack of nitrate data for all the years from 2011-2015, the latest cancer data available. The Safe Drinking Water Act passed by the United States Congress requires that the drinking water treatment system distribute the results of primary contaminants and strongly encourages the distribution of the results for secondary contaminant analysis to the users. Many drinking water systems have just recently started to make the results freely available over the internet. When the next SERS data are released for 20152020, we will be able to study the relationship between nitrate concentration and incidence rates of cancer for the same duration and with the five-year data for nitrates.

\section{Results and Discussion}

A total of 1,355 unique nitrate values were transcribed for the drinking water across the 19 states and 142 counties analyzed in the study. The average maximum nitrate value found in the drinking water was $2.2 \mathrm{ppm}$ and only eight values were above the EPA approved threshold of $10 \mathrm{ppm}$. Upon transforming the nitrate data to five year averages, data distribution shows that most of the country indeed receive water with nitrate concentration less than 2ppm (Figure 1). This indicates that the majority of the population analyzed in the current study receive safe drinking water in reference to nitrate concentration.

The results of the Pearson Correlation analysis between the five-year average incidence rates of cancer and five-year average maximum nitrate concentrations are shown in Table 1. Of the thirteen types analyzed, only four cancer types show any statistically significant correlation with the nitrate concentration in drinking water $(\mathrm{p}<0.05)$. For four cancer types: kidney and renal pelvic, larynx, lung and bronchus, and oral and pharynx, the correlation coefficients are negative and statistically significant. This indicates that as the concentration of nitrates in drinking water increases within safe limits, the observed cancer incidence rates decreases in the population. This signifies a preventative effect of nitrates. To confirm the statistical correlation between nitrate concentrations in drinking water and incidence rates of cancer, linear regression models were developed. As seen in Table 1 , the same four cancer types were found to have coefficients to be statistically significant $(p<0.05)$ as observed for the Pearson Correlation analysis. This confirms the observed correlation between nitrates and incidence rates of the cancer.

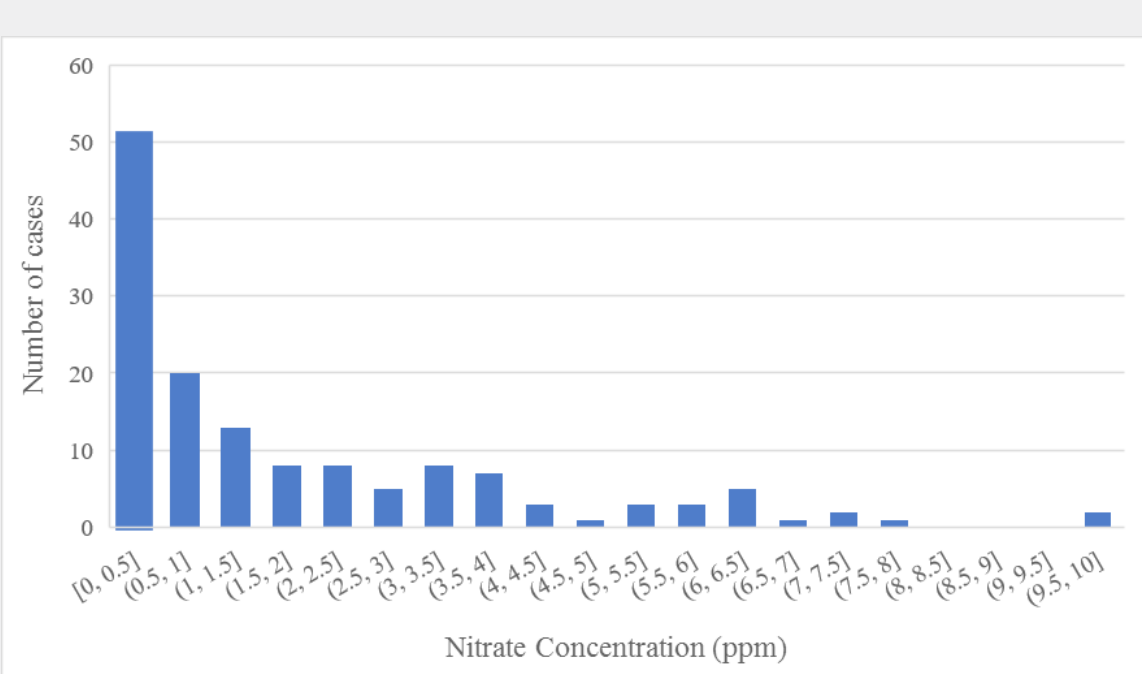

Figure 1: Data distribution of the 5 year maximum nitrate concentration present in the drinking water systems that were analyzed in the current study. 


\section{International Journal of Environmental Sciences \& Natural Resources}

Table 1: Pearson correlation coefficients and linear regression coefficients showing relationship between nitrate concentration in drinking water (independent variable) and incidence rates of cancer (dependent variable).

\begin{tabular}{|c|c|c|}
\hline Cancer Type & Pearson Correlation Coefficient & Linear Regression Coefficient \\
\hline Bladder & -0.05 & 0.05 \\
\hline Brain and Nervous System & -0.05 & -0.18 \\
\hline Breast and Ovarian & -0.06 & -0.06 \\
\hline Esophagus & -0.17 & $-0.23^{*}$ \\
\hline Kidney and Renal Pelvic & $-0.22^{*}$ & $-0.16^{*}$ \\
\hline Larynx & $-0.39^{*}$ & -0.03 \\
\hline Leukemia & -0.04 & 0.08 \\
\hline Lung and Bronchus & 0.12 & $-1.72^{*}$ \\
\hline Melanoma of the Skin & $-0.32^{*}$ & 0.17 \\
\hline Non-Hodgkin's Lymphoma & 0.02 & 0.14 \\
\hline Oral and Pharynx & 0.14 & $-0.22^{*}$ \\
\hline Thyroid & $-0.31^{*}$ & 0.15 \\
\hline
\end{tabular}

*Values that are statistically significant $(p<0.05)$.

To understand if the relationship between nitrates and incidence rates of cancer are influenced by race and sex, regression analysis models were obtained with incidence rates of cancer obtained for each combination of sex (male and female) and race (Asian, Black, Hispanic, American Indian, and White). P values of the coefficients for nitrate concentrations against incidence rates of cancer for each given sex and race is shown in Table 2. As seen in Table 2, race and sex play a significant role in determining the causative and preventative effects of nitrate. The white population seems to be more impacted by the concentration of nitrates in general whereas no statistically significant correlation was observed for Asians and American Indians for all the types of cancer analyzed, irrespective of the sex.

Table 2: $P$ values of the linear regression coefficient for nitrate concentration in drinking water when modeled to predict the incidence rates of cancer. The values that are $<0.05$ are in bold font.

\begin{tabular}{|c|c|c|c|c|}
\hline & Kidney and Renal Pelvic & Larynx & Lung and Bronchus & Oral and Pharynx \\
\hline Male-White & 0.051 & $\mathbf{0 . 0 0 0}$ & $\mathbf{0 . 0 0 0}$ & $\mathbf{0 . 0 0 0}$ \\
\hline Female - White & 0.089 & $\mathbf{0 . 0 0 0}$ & $\mathbf{0 . 0 1 3}$ & $\mathbf{0 . 0 0 1}$ \\
\hline Male-Asian & 0.515 & 0.499 & 0.298 & 0.16 \\
\hline Female - Asian & 0.231 & 0.362 & 0.608 & 0.06 \\
\hline Male - Black & 0.29 & $\mathbf{0 . 0 0 1}$ & $\mathbf{0 . 0 0 4}$ & 0.138 \\
\hline Female - Black & 0.198 & 0.339 & 0.617 & 0.063 \\
\hline Male - Hispanic & 0.111 & $\mathbf{0 . 0 2}$ & $\mathbf{0 . 0 0 6}$ & 0.024 \\
\hline Female - Hispanic & 0.907 & $\mathbf{0 . 0 1 9}$ & 0.359 & Too few cases \\
\hline Male - American Indian & 0.551 & Too few cases & 0.076 & 0.138 \\
\hline Female - American Indian & 0.169 & Too few cases & 0.18 & \\
\hline
\end{tabular}

It is important to note that the regression models presented in the study only allows us to see if there is a relationship between nitrate concentration in drinking water and the incidence rates of cancer. The primary reason being the cancer data was presented as an average for 2011-2015 years, but nitrate data was average of 2012- 2017 years, with not all counties having all five year average values. Recently, Shah et al. [10] reported that there are increased incidence rates of cancer rates in counties with high precipitation (rainfall and snowfall) [10]. While no direct cause was determined in the study, we investigated if there is any relationship between the nitrate concentration in drinking water and precipitation in a given county. Correlation analysis showed that the two variables have statistically significant negative correlation $(r=-0.26$, $p$ $<0.05$ ). This implies that water from counties receiving high precipitation has low level of nitrates in drinking water. It is well established that as the precipitation increases in a given area, it 
leaches the nitrates from the soil into the ground water [11,12]. In the area with high precipitation, once critical level of rainfall has been reached where nitrates have been washed off, increasing precipitation in fact could be diluting the nitrate concentration in the drinking water.

Results from this study show that some nitrate concentrations in drinking water is beneficial to human body and seems to be having a positive relationship in decreasing the incidence rates of Kidney and Renal Pelvic, Larynx, Lung and Bronchus, and Oral and Pharynx cancer. We believe that the influence of demographic variables on the relationship between nitrate concentrations and incidence rates of cancer can be attributed to the different microbiomes present in each population type. Nitrates in drinking water are converted to nitrites by the oral microflora present in the humans [13]. The nitrites under acidic conditions are known to form various biologically active reactive nitrogen intermediates (RNIs) [14]. These RNIs have shown to have beneficial effects on human body including killing pathogen, increasing gastric mucosal integrity, and preventing oral cavities and fungal skin infections. Differences in oral microbiomes in different races and sex could impact the production of RNIs and possible effects on cancer. We understand that further studies are needed to confirm the observed correlation, and if the correlation is confirmed, elucidate the mechanism of action. However, if the results observed in the current study are confirmed, it is possible to envisage probiotic strategies that selectively encourage the growth of nitrate reducing bacteria in the oral cavity and decrease the prevalence of cancer in general population.

\section{Author Contribution}

The study was conceived by VS. AS extracted the data. VS and AS performed statistical analysis, interpreted findings and drafted the manuscript.

\section{References}

1. Murphy SL, Xu JQ, Kochanek KD, Arias E (2018) Mortality in the United States, 2017. NCHS Data Brief, No. 328. Hyattsville, MD: National Center for Health Statistics.
2. Goodwin JS, Freeman JL, Freeman D, Nattinger AB (1998) Geographic variations in breast cancer mortality: do higher rates imply elevated incidence or poorer survival? American Journal of Public Health 88(3): 458-460.

3. Perdue DG, Perkins C, Jackson-Thompson J, Coughlin SS, Ahmed F, et al. (2008) Regional differences in colorectal cancer incidence, stage, and subsite among American Indians and Alaska Natives, 1999-2004. Cancer: Interdisciplinary International Journal of the American Cancer Society 113(S5): 1179-1190.

4. Sariego J (2009) Patterns of breast cancer presentation in the United States: does geography matter? The American Surgeon 75(7): 545550 .

5. Gulis G, Czompolyova M, Cerhan JR (2002) An ecologic study of nitrate in municipal drinking water and cancer incidence in Trnava District, Slovakia. Environmental research 88(3): 182-187.

6. Weyer PJ, Cerhan JR, Kross BC, Hallberg GR, Kantamneni J, et al. (2001) Municipal drinking water nitrate level and cancer risk in older women: the Iowa Women's Health Study. Epidemiology 12(3): 327-338.

7. Gulis G, Czompolyova M, Cerhan JR (2002) An ecologic study of nitrate in municipal drinking water and cancer incidence in Trnava District, Slovakia. Environmental research 88(3): 182-187.

8. Morales-Suarez-Varela MM, Llopis-Gonzalez A, Tejerizo-Perez ML (1995) Impact of nitrates in drinking water on cancer mortality in Valencia, Spain. European journal of epidemiology 11(1): 15-21.

9. Ward MH, Mark SD, Cantor KP, Weisenburger DD, Correa-Villasenor A, et al. (1996) Drinking water nitrate and the risk of non-Hodgkin's lymphoma. Epidemiology 7(5): 465-471.

10. Shah V, Rieger RH, Pan LX (2019) Precipitation and Climate Zone Explains the Geographical Disparity in the Invasive Cancer Incidence Rates in the United States. Environmental Engineering Science 36(12): 1452-1458.

11. Wetselaar R (1962) Nitrate distribution in tropical soils. Plant and Soil 16(1): 19-31.

12. Canter LW (2019) Nitrates in groundwater. Routledge.

13. Lundberg JO, Weitzberg E, Cole JA, Benjamin N (2004) Nitrate, bacteria and human health. Nature Reviews Microbiology 2(7): 593-602.

14. Duncan C, Li H, Dykhuizen R, Frazer R, Johnston P, et al. (1997) Protection against oral and gastrointestinal diseases: importance of dietary nitrate intake, oral nitrate reduction and enterosalivary nitrate circulation. Comparative Biochemistry and Physiology Part A: Physiology 118(4): 939-948.

Your next submission with Juniper Publishers will reach you the below assets

- Quality Editorial service

- Swift Peer Review

- Reprints availability

- E-prints Service

- Manuscript Podcast for convenient understanding

- Global attainment for your research

- Manuscript accessibility in different formats ( Pdf, E-pub, Full Text, Audio)

- Unceasing customer service

Track the below URL for one-step submission https://juniperpublishers.com/online-submission.php 